\title{
Deformation and breakage of biofuel wood pellets
}

\author{
Alexander Russell ${ }^{a,}{ }^{*}$, Sylvia Larsson ${ }^{b,{ }^{*}}$, Shishir Shekhar ${ }^{c}$, Isaac Solomon ${ }^{d}$, \\ Hamid Salehi ${ }^{\mathrm{b}}$, Jordi Subirana ${ }^{\mathrm{b}}$, Robert Samuelsson ${ }^{\mathrm{b}}$ \\ andependent Researcher, 68165 Mannheim, Germany \\ ${ }^{b}$ Swedish University of Agricultural Sciences, Department of Forest Biomaterials and Technology, \\ Skogsmarksgränd, 90183 Umeå, Sweden \\ 'Independent Researcher, Chennai 603002, India \\ ${ }^{d}$ Independent Researcher, Kaunas 51373, Lithuania \\ *Correspondence may be addressed to: \\ Alexander Russell (alexander.immanuel@gmail.com) \\ Sylvia Larsson (Sylvia.Larsson@slu.se)
}

\begin{abstract}
A convenient approach to employ an elliptic load-deformation elastoplastic approximation has been proposed and used to evaluate the mechanical behavior of pinewood biofuel pellets from lab-scale compressive load-deformation measurements. Verification of model predictions has been attempted against apparent finite element method based simulations. A database of essential mechanical properties has been established. This submission is intended as a model for being able to study the deformation and breakage behavior using lab-scale compression tests.
\end{abstract}

Keywords biomass, biofuel, pellets, wood, strength, breakage 


\section{Introduction and scope}

Woody materials are a key contributor to solid biofuels. For instance, $46 \%$ of the total bio-based energy supply in 2014's Sweden can be attributed to wood fuels alone (Swedish Energy Agency, 2015). Woody biomass can be converted into pellets to facilitate ease in handling, to improve product performance and to minimize material loss. With the current global demand for woody biofuel pellets (Whittaker and Shield, 2017) and the potential future requirements (for instance, the recent note from Börjesson et al., 2017 predicting forest biomass demand for energy purposes to rise up to approximately 62-70 \pm 35 TWh/a by 2050 from today's demand (de Jong et al., 2017) of 20 TWh/a in aid of one of European Union's key objectives (EC Communication from EU Parliament, 2017) for 2050), the industry has and continues to constantly strive towards - meeting supply demands, delivering consistent improvements in manufacturing and in assuring uncompromising product quality.

Such a demanding challenge has thus far been approached at the expense of enormous material, equipment, and personnel resources; especially in endeavors impacting equipment design, process design, scale-up/down, optimization and trouble-shooting of unit operations such as screw-conveying and silo-filling/discharge. Utilizing computational simulations can be immensely beneficial as they offer the potential to aid such needs with significantly lesser investments of material, personnel and time resources.

Albeit, generating representative dynamics and kinematics of bulk materials in unit operations (be it considering only solid-solid or also solid-fluid interactions) has been a grand challenge in every industrial product genre. This may be attributed to the fact that simulations' accuracy depends primarily on - (a) the contact model chosen to illustrate realistic physics of discrete contacts in the bulk system, and (b) the distribution of geometries, material and mechanical properties assigned to the discrete components of the bulk system. With literature as of today, one can find physics-intricate contact models (which may be computationally expensive), as well as studies employing computationally less 
expensive contact models (which may exclude certain aspects of contact physics) yet satisfactorily, mimic system behavior in a unit operation. Ultimately, the choice of an appropriate contact model may be meaningfully ascertained, only when a holistic understanding of the contact behavior of specimens is established; which may be done by evaluating the mechanical behavior of single specimens in convenient lab-scale tests such as compression or drop tests.

Therefore, to employ computational simulations as an integral option in designing and optimizing industrial processes involving biofuel wood pellets, as a first step - material mechanics need to be established. As of today, besides the contributions (Li and Liu, 2000; Temmerman et al., 2006; Bradfield and Levi, 1984; Chen et al., 1989; Kaliyan and Morey, 2009; Samuelsson et al., 2012: Larsson et al., 2013, Larsson and Samuelsson, 2017; Oveisi et al., 2013), where influences of physical and material properties on the resistance to deformation/breakage in terms of durability have been recorded, there exists no literature treating the constitutive properties. The authors attempt to address the need in this communication.

\section{Proposed modeling approach}

As biofuel wood pellets in their original fresh state resemble inhomogeneous, nonisotropic solids that exhibit a non-linear rate of reduction in porosity and densification prior to volumetric elastic deformation, a comprehensive solid mechanics modeling approach from origin until structural collapse by cracking may be inappropriate. This can be noted from a typical load-deformation plot (see Figure 1) constructed with data measured in a uniaxial compression test; for reference to detailed fundamentals for generating load-deformation plots from raw measurements, one may turn to Johnson (1985). Each pellet begins by deforming with: (i) an initial deformation phase $O-O^{\prime}$ indicating a certain soft 
densification ${ }^{1}$, followed by (ii) a piecewise linear elastic deformation phase until reaching a point of maximum stress $Y$ that initiates plastic yielding, followed by (iii) a piecewise non-linear plastic deformation phase that extends until (iv) breakage $B$ of the pellet.

Figure 1: $\quad$ Characteristic load-deformation behavior illustrative of all samples. The presented data is of a single pellet chosen from sample class PPT 45 (Table 1).

Although the material's structural transformation through each of these phases is continuous, the transition between phases i.e. points $O^{\prime}, Y$ and $B$ can be approximated from the change of gradients in the load-deformation data. The initial volumetric densification (phase i) is merely a cumulative response of rearrangement of loosely packed primary particles, void-filling leading to textural densification; all dependent on the material's structural inhomogeneity and would be meaningless to be modeled.

At the end of the phase (i), one may consider the pellet to have reached a solid textural state. Assuming the pellet at this stage to be homogenous and isotropic with deformable contacts, the contact deformation may be modeled and the strain-dependent evolution of contact properties may be determined using an elliptic load-deformation estimation of elastoplasticity assuming a constant resistance to transverse strain.

The elastic stiffness $k$ can be approached as secant stiffness by determining the first spatial derivative of the contact force according to

$k=\frac{d}{d \delta} f=\frac{f_{e l \max }}{\delta_{e l, \max }}=\frac{f_{Y}}{\delta_{Y}}$

where $f_{Y}$ and $\delta_{Y}$ respectively refer to the maximum elastic contact force and displacement at point $Y$.

\footnotetext{
${ }^{1}$ in the direction of the principal strain path.
} 
The modulus of elasticity $E$ can be derived from the elastic stiffness as

$E=k \cdot--$

where $I_{0}$ and $A_{0}$ refer to the initial sample length and initial contact area respectively.

The deformation work done i.e. the strain energy absorbed until yielding $W_{Y}$ and until breakage, $W_{B}$ can be directly calculated as

$W_{Y}=\int_{\delta_{0}}^{\delta_{Y}} f d \delta=\sum f_{0} \cdot \delta_{o}+\ldots \ldots f_{Y} \cdot \delta_{Y}$

and as

$W_{Y}=\int_{\delta_{0}}^{\delta_{B}} f d \delta=\sum f_{0} \cdot \delta_{0}+\ldots \ldots f_{B} \cdot \delta_{B}$

respectively; where $f_{B}$ and $\delta_{B}$ respectively refer to the maximum contact force and deformation at point

B.

On one hand, Eqs. (1) and (2) remain valid at all conditions irrespective of the system's strain rate i.e. can be used to map the stiffness, both when the material remains static to quasi-static (e.g. during storage in a silo) as well as when in motion at high velocities (e.g. during conveying by a conveyor belt). On the other hand, Eqs. (3) and (4) that hold good within static and quasi-static conditions, may lead to underestimations when predicting the same at dynamic conditions (due to several reasons elaborated in Russell et al., 2015). This non-equivalency remains since dynamic stressing events are characterized by a strain rate c.a. $10^{5}$ to $10^{6}$ times that of quasi-static events (Russell et al., 2014).

Nevertheless, by assuming that all the kinetic energy of a (moving) pellet colliding on a rigid surface (at rest) is spent in crack generation, one can predict the collision velocity required to generate the same strain energy initiating plastic yielding and breakage (equivalent to that at static stressing i.e. Eqs. (3) and (4)) as 
$v_{Y}=\sqrt{2 \cdot \frac{W_{Y}}{m_{p}}}$

and

$v_{B}=\sqrt{2 \cdot \frac{W_{B}}{m_{p}}}$

respectively; where $m_{p}$ is the pellet mass and $v_{Y}$ and $v_{B}$ are the predicted collision velocities.

\section{Materials and Methods}

\subsection{Test material}

The pellets utilized in this study were produced at the Biomass Technology Centre, Umeå, Sweden, according to an experimental design and procedures which are fully described in Larsson and Samuelsson (2017). Sample batches were taken at selective intervals from an 18 ton storage pile made of Scots pine (Pinus sylvestris L.) sawdust which was plane dried, hammer milled, moisture content adjusted, conditioned by steam, and subsequently pelletized in a ring die pelletizer to cover a full factorial design of four different storage times, three levels of feedstock moisture content, and two steam conditioning levels. Pellets from 16 of these pellet assortments were chosen as model test materials for this study. Repeated sampling was performed during pellet production (three, 1 minute long sampling periods) and allowed to cool down in open air. The three samples from each batch were mixed and then reduced, using a riffle box sample divider, to a small enough sample to provide 20 pellets with a length $>4.5 \mathrm{~mm}$. The chosen pellets were cut to equal length with a Japanese saw (Malco Razorsaw 180) with a blade thickness of $0.3 \mathrm{~mm}$ and a tooth distance of $1.5 \mathrm{~mm}$. All pellets resembled a cylindrical shape with a mean diameter $d_{0} \approx 8.08 \mathrm{~mm}$ and a mean length $I_{0} \approx 4.5 \mathrm{~mm}$. Table 1 summarizes the key information presumed most relevant for this study. The pellet length (which was shorter than the general $20-30 \mathrm{~mm}$ length of commercial pellets) was restricted by the length of the 
pellets of the lower quality assortments. For these assortments, the maximum obtained pellet length was $4.5 \mathrm{~mm}$. Consequently, compression tests for all of the assortments were performed on pellets of this length.

Table 1: $\quad$ Summary of production settings and resulting physical and mechanical properties of the pellet samples.

\subsection{Experimental test method}

Single pellets were tested by uniaxial quasi-static compression using an Instron 3366 strength tester (Figure 2). Each pellet was placed on its curved surface on the lower punch and the upper punch was brought in contact with the pellet such that a punch-pellet-punch contact was obtained, from whereon the pellet was laterally compressed at a displacement-controlled rate of approximately 0.002 $\mathrm{mm} / \mathrm{s}$ until its breakage. To achieve representative results, 20 single pellets were tested from each of the 16 pellet assortments.

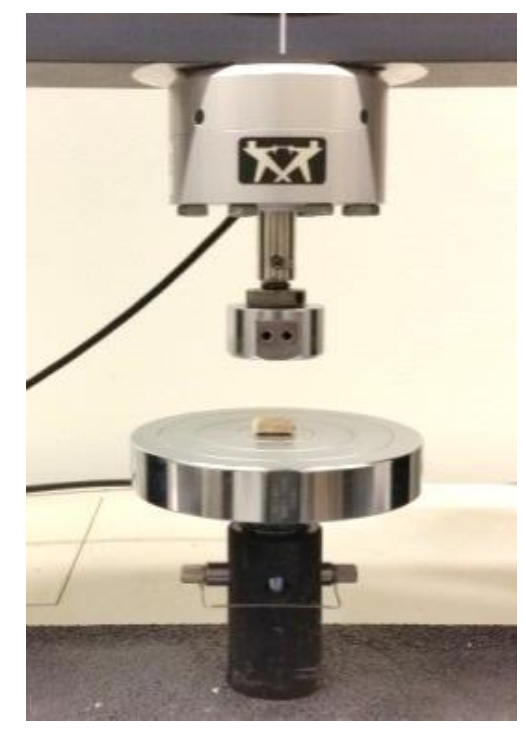

Figure 2: $\quad$ Single pellet uniaxial compression setup.

\subsection{Simulation model}


A three-dimensional finite element method model was constructed and solved to simulate the experimental behavior using SOLIDWORKS ${ }^{\circledR}$ (Student edition, Academic year 2016-2017). Geometries were constructed based on the experimental set-up, material properties of the steel punches were taken from the software's in-built material library, material properties of the pellets were taken from literature, physics-controlled meshing was performed, materials were assigned as linear elastic, and the model was solved for static conditions; all details are summarized in Table 2. The simulations were observed in terms of the von-Mises stress at three points - (a) prior stressing, (b) at origin of plastic yielding and (c) at instant of breakage initiation, for sample set PPT36 (chosen with the intention to consider one with water content relatively on the lower side, Table 1).

Table 2: $\quad$ Summary of the simulation model details.

\section{Results and Discussion}

\subsection{Model-based mechanical properties}

Figure 3 presents log-normal distributions of the elastic stiffness of samples (acc. to Eq. (1)). One may note that the modulus of elasticity (acc. to. Eq. (2)) will also follow identical trends as it is merely a measure of the same altered by a certain constant. Figure 4 and Figure 5 present log-normal distributions of the collision velocity required to initiate plastic yielding and breakage of the pellet (acc. to Eqs. (5) and (6)) respectively. The evaluated properties have also been presented as mean values in the Appendix (Table A).

Figure 3: Log-normal distributions of the elastic stiffness of samples showing influences of (a) premanufacturing sawdust storage time, (b) manufacturing steam rate and (c) feedstock moisture content. 
Figure 4: $\quad$ Log-normal distributions of the collision velocities required to initiate yielding in samples showing influences of (a) pre-manufacturing sawdust storage time, (b) manufacturing steam rate and (c) feedstock moisture content.

Figure 5: $\quad$ Log-normal distributions of the collision velocities required to initiate breakage in samples showing influences of (a) pre-manufacturing sawdust storage time, (b) manufacturing steam rate and (c) feedstock moisture content.

The results indicate that the material's resistance to deformation and breakage varies - (a) directly with the pre-manufacturing sawdust storage time, (b) directly with the manufacturing steam rate and (c) directly with the moisture content of the feedstock.

These observations are in reasonable agreement with the following:

- Pre-manufacturing softwood sawdust storage time is positively correlated with pellet durability (Samuelsson et al., 2009; Samuelsson et al., 2012). During the storage of softwood sawdust, the content of resins and fatty acids (extractives) is reduced (Nielsen et al. 2009, Samuelsson et al., 2012). Softwood extractives act as plasticizers and lubricants (reducing the backpressure in the pelletizing channel) and fatty substances prevent close contact between the bonding sites of the lignocellulose particles (Nielsen et al., 2010).

- By steam conditioning, heat and moisture are added to the feedstock material. Feedstock particles are thereby softened so that their surfaces align more easily in the compaction process. This provides better conditions for interparticle bonding and reduces the energy consumption of the pelletizing process (Segerström and Larsson, 2014). However, the increase in feedstock moisture content affects pellet quality and pelletizing process in several ways (see below), and an optimum steam level has to be found for each feedstock material. 
- The optimum moisture content for maximum pellet durability was found at the higher moisture content levels, as also found by Samuelsson et al. (2012). However, since feedstock moisture has multiple effects by providing particle bonding through softening of particles and formation of liquid bridges and it is also lubricating the pelletizing process, and that the level of these effects is dependent on the specific feedstock materials' hygroscopic properties, the optimum moisture content is not a linear parameter. For the specific pellet feedstock used in this study, the optimum moisture content for maximum durability is positively correlated with storage time. This is hypothesized by Samuelsson et al. (2012) to be due to the following: i) stored materials have lower content of bonding-inhibiting extractives, providing more available sites for water molecules to bridge and, ii) since there is a lower amount of and lubricating fatty acids and resins, a higher amount of water (which also acts as a lubricant) is allowed before deteriorating the back-pressure in the press channels. Vice versa: fresh materials have higher contents of fatty extractives that block the feedstock particles' liquid bonding sites and decrease pellet durability. In addition, with a lower number of available sites, free water will be present in the feedstock material at a lower moisture content. Free water and extractives, have a strong lubricating effect and deteriorates the back-pressure in the press channels.

\subsection{Empirical design estimate}

To holistically view the influences of the pre-manufacturing sawdust storage time, the manufacturing steam rate and the moisture content on the material's resistance to deformation and breakage, one may summarize them all in terms of an empirical dimensionless estimate. For instance, one can define such a dimensionless estimate $\psi$ as in Eq. (7). 
$\Psi=$

where $g$ is the acceleration due to gravity.

Figure 6 presents an empirical design map relating to the collision velocities required for initiating yield and breakage versus this empirical dimensionless estimate.

Figure 6: $\quad$ Map of collision velocities initiating yield and breakage versus an empirical dimensionless design estimate.

\subsection{Simulated sample response}

Figure 7 presents the three-dimensional finite element method simulated model (sample PPT 36) response during compression. The simulated macroscopic change in shape is in line with the experimental observations and the distribution of the stress profiles are in line with the general theory of elasticity.

If one would consider a two-dimensional sample slice which would be a sphere, assuming perfect contact plasticity and neglecting the tangential spread at the circumference of the contact during stressing - a Pythagorean right triangle can be assumed to be formed with its three edges: (1) at the center of contact, (2) at the center of sample and (3) at the circumference of contact; for instance, refer to Huang et al. (2014) and Russell et al. (2018). From the deformation measurements and the sample length $4.5 \mathrm{~mm}$, one would arrive at the three-dimensional rectangular contact areas of 11.54 and $14.44 \mathrm{~mm}^{2}$ formed at instants of yield and breakage. This would, in turn, translate to contact pressures of 19.41 and $31.03 \mathrm{MPa}$ at instants of yield and breakage respectively. The presented simulations in Figure 7 illustrate the validity and satisfactory accuracy of this approach. 
Figure 7: $\quad$ Three-dimensional finite element based simulations of the sample response during compression: (a) at zero load, (b) at yield load, and (c) at breakage load measured for sample class PPT 36, see Table 1.

\section{Conclusion}

The mechanical properties of biofuel wood pellets may be determined by approximating the load-deformation behavior, measured for instance by lab-scale compression or drop tests. Upon stressing, each pellet initially densifies by reduction in porosity, and thereon deforms with a constant resistance to transverse strain until yielding, and further on with a slightly reduced constant resistance until breakage. This pattern has been shown in previous studies on biomass pellets (e.g. by Stelte, et al. 2011) and can be considered as typical for fibrous materials, such as woody and agricultural biomass.

Having thus established a holistic understanding of the contact behavior of single specimens and the corresponding strain-dependent evolution of key contact properties, the grand challenge of employing computational methods to simulate physics in every discrete element whereby cost- and time-framed elucidation, design, and optimization of manufacturing and subsequent downstream unit operations with bulk materials may now be attempted.

\section{Nomenclature}

$\begin{array}{lll}\text { Symbol } & \text { Description } & \text { Unit } \\ \delta & \text { contact deformation } & \mathrm{Mm} \\ \psi & \text { empirical design estimate } & - \\ \text { A } & \text { contact area } & \mathrm{mm}^{2}\end{array}$




\begin{tabular}{|c|c|c|}
\hline d & diameter & $\mathrm{Mm}$ \\
\hline $\mathrm{E}$ & modulus of elasticity & $\mathrm{MPa}$ \\
\hline$f$ & contact force & $\mathrm{N}$ \\
\hline g & acceleration due to gravity & $\mathrm{m} / \mathrm{s}^{2}$ \\
\hline k & contact stiffness & $\mathrm{kN} / \mathrm{m}$ \\
\hline I & length of sample & $\mathrm{Mm}$ \\
\hline $\mathrm{m}$ & mass & g \\
\hline v & contact/collision velocity & $\mathrm{m} / \mathrm{s}^{2}$ \\
\hline W & strain energy absorbed by stressing & $\mathrm{mJ}$ \\
\hline \multicolumn{3}{|c|}{ Indices } \\
\hline B & point of crack initiation & \\
\hline el & elastic & \\
\hline $\max$ & maximum & \\
\hline $\mathrm{O}$ & origin point of stressing & \\
\hline $\mathrm{O}^{\prime}$ & \multicolumn{2}{|c|}{ assumed origin of homogeneous isotropic state } \\
\hline $\mathrm{p}$ & pellet & \\
\hline Y & point of incipient plastic yielding & \\
\hline 0 & initial state & \\
\hline
\end{tabular}

\section{References}

Bradfield, J., Levi, M.P., 1984. Effect of species of wood to bark ratio on pelleting of southern woods, Forest Products J. 34, 61-63. 
Börjesson, P., Hansson, J., Berndes, G., 2017. Future demand for forest-based biomass for energy purposes in Sweden, For. Ecol. Manage. 383, 17-26.

Chen, P.Y.S., Haygreen, J.G., Graham, M.A., 1989. An evaluation of wood/coal pellets made in a laboratory pelletizer, Forest Products J. 39, 53-58.

Communication from the European Commission to the European Parliament, the Council, the European Economic, and Social Committee and the Committee of the regions, 2011. A roadmap for moving to a competitive low carbon economy in 2050, COM 112 final, Brussels, pp. 1-15; last accessed on 04-Aug-2017 at http://eur-lex.europa.eu/legalcontent/EN/TXT/PDF/?uri=CELEX:52011DC0112\&from=EN.

de Jong, J., Akselsson, C., Egnell, G., Löfgren, S., Olsson, B., 2017. Realizing the energy potential of forest biomass in Sweden - how much is environmentally sustainable?, For. Ecol. Manage. 383, 3-16.

Finell, M., Arshadi, M., Gref, R., Scherzer, T., Knolle, W., \& Lestander, T. 2009. Laboratory-scale production of biofuel pellets from electron beam treated Scots pine (Pinus silvestris L.) sawdust. Radiation Physics and Chemistry. 78, 281-287.

Nielsen, N. P. K., Gardner, D. J., \& Felby, C. (2010). Effect of extractives and storage on the pelletizing process of sawdust. Fuel, 89(1), 94-98.

Huang, J., Xu, S., Yi, H., Hu, S., 2014. Size effect on the compression breakage strengths of glass particles, Powder Technol. 286, 86-94.

Johnson, K. L., 1985. Contact Mechanics, Cambridge University Press, Cambridge.

Kaliyan, N., Morey, R.V., 2009. Factors affecting strength and durability of densified biomass products, Biomass Bioenergy 33, 337-359.

Kretschmann, D.E., Green, D.W., 1996. Modeling moisture content-mechanical property relationships for clear southern pine, Wood. Fiber Sci. 28, 320-337. 
Larsson, S.H., Rudolfsson, M., Nordwaeger, M., Olofsson, I., Samuelsson, R., 2013. Effects of moisture content, torrefaction temperature, and die temperature in pilot-scale pelletizing of torrefied Norway spruce, Applied Energy 102, 827-832.

Larsson, S.H., Samuelsson, R., 2017. Prediction of ISO 17831-1:2015 mechanical biofuel pellet durability from single pellet characterization, Fuel Process. Technol. 163, 8-15.

Li, Y., Liu, H., 2000. High-pressure densification of wood residues to form an upgraded fuel, Biomass Bioenergy 19, 177-186.

Nielsen, N.P.K., Gardner, D.J., \& Felby, C. 2010. Effect of extractives and storage on the pelletizing process of sawdust. Fuel, 89, 94-98.

Nielsen, N.P.K., Norgaard, L., Strobel, B.W., \& Felby, C. 2009. Effect of storage on extractives from particle surfaces of softwood and hardwood raw materials for wood pellets. European Journal of Wood and Wood Products, 67, 19-26.Oveisi, E., Lau, A., Sokhansanj, S., Lim, C.J., Bi, X., Larsson, S.H., Melin, S., 2013. Breakage behavior of wood pellets due to free fall, Powder Technol. 235, 493-499.

Russell, A., Müller, P., Shi, H., Tomas, J., 2014. Influences of loading rate and preloading on the mechanical properties of dry elasto-plastic granules under compression, AIChE J. 60, 40374050.

Russell, A., Schmelzer, J., Müller, P., Krüger, M., Tomas, J., 2015. Mechanical properties and breakage probability of compact agglomerates, Powder Technol. 286, 546-556.

Russell, A., Šibanc, R., Dreu, R., Müller, P., 2018. Mechanics of pharmaceutical pellets - Constitutive properties, deformation and breakage behavior, J. Pharm. Sci. 107, 571-586.

Samuelsson, R., Thyrel, M., Sjöström, M., Lestander, T.A. 2009. Effect of biomaterial characteristics on pelletizing properties and biofuel pellet quality. Fuel Processing Technology 90, 1129-1134. 
Samuelsson, R. Larsson, S.H., Thyrel, M., Lestander, T.A., 2012. Moisture content and storage time influence the binding mechanisms in bio fuel wood pellets, Applied Energy 99, 109-115.

Swedish Energy Agency, 2015. Energiläget, Eskilstuna (in Swedish).

Segerström, M., \& Larsson, S.H. 2014. Clarifying sub-processes in continuous ring die pelletizing through die temperature control. Fuel Processing Technology, 123, 122-126.

Stelte, W., Holm, J.K., Sanadi, A.R., Barsberg, S., Ahrenfeldt, J., \& Henriksen, U.B. 2011. A study of bonding and failure mechanisms in fuel pellets from different biomass resources. Biomass and bioenergy, 35, 910-918.

Temmerman, M., Rabier, F., Jensen, P.D., Hartmann, H., Böhm, T., 2006. Comparative study of durability test methods for pellets and briquettes, Biomass Bioenergy 30, 964-972.

Whittaker, C., Shield, I., 2017. Factors affecting wood, energy grass and straw pellet durability - A review, Renewable and Sustainable Energy Reviews 71, 1-11.

Witomski, P., Krajewski, A., Kozakiewicz, P., 2014. Selected mechanical properties of scots pine wood from antique churches of central Poland, Eur. J. Wood. Prod. 72, 293-296. 


\section{Appendix}

Table A: $\quad$ Summary of the model-based evaluated mechanical properties

Page 17 of 17 


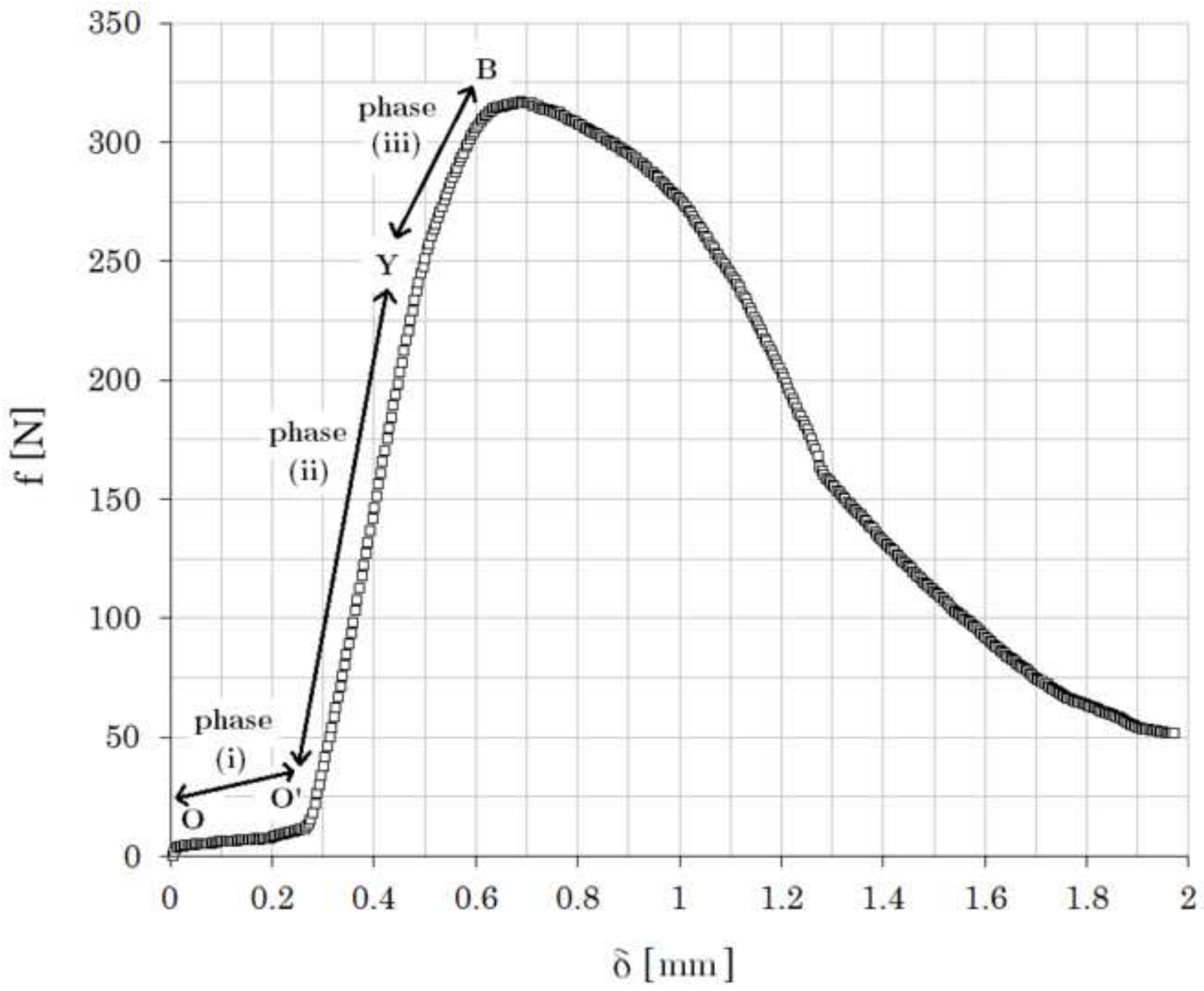




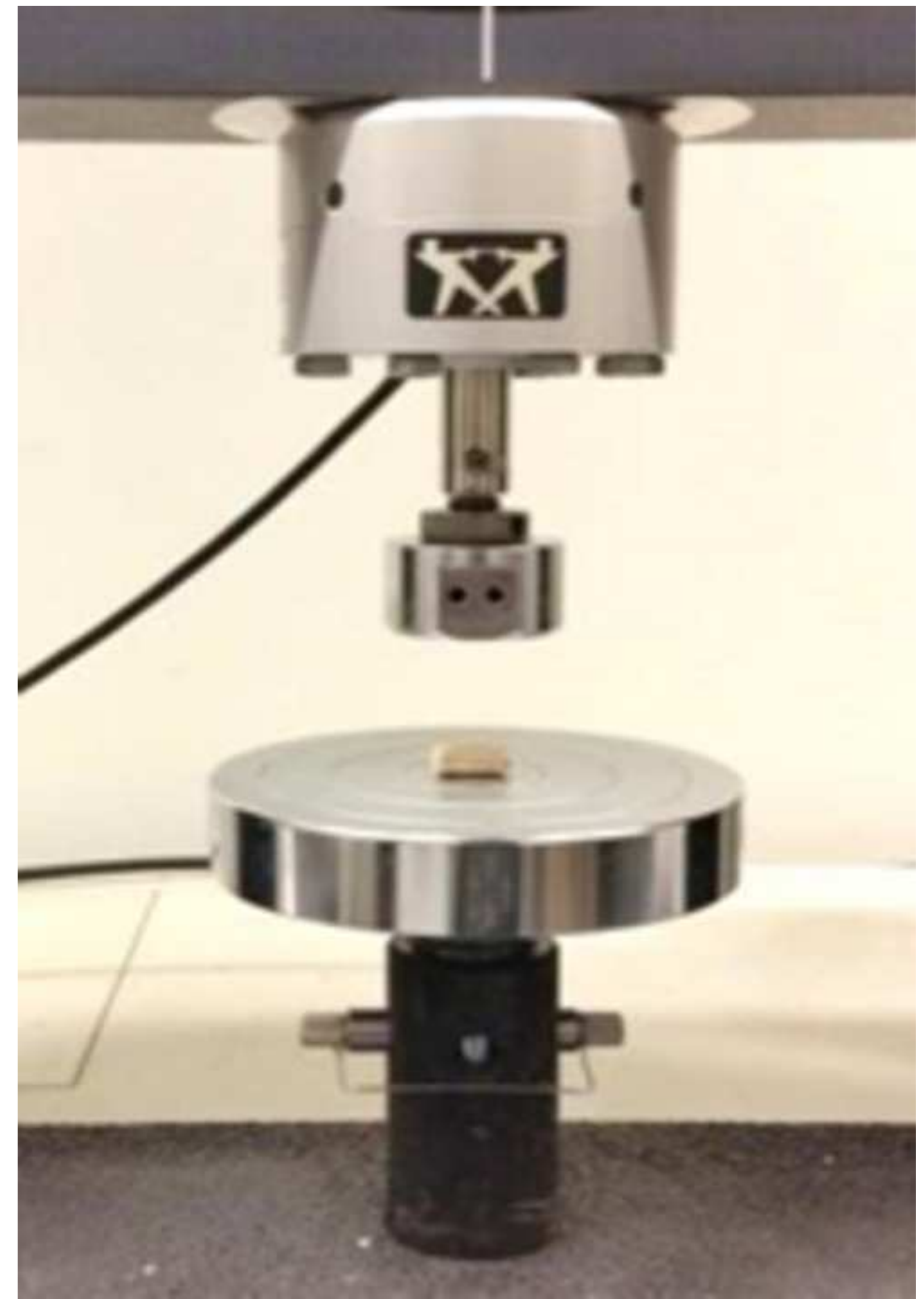

Figure 2 


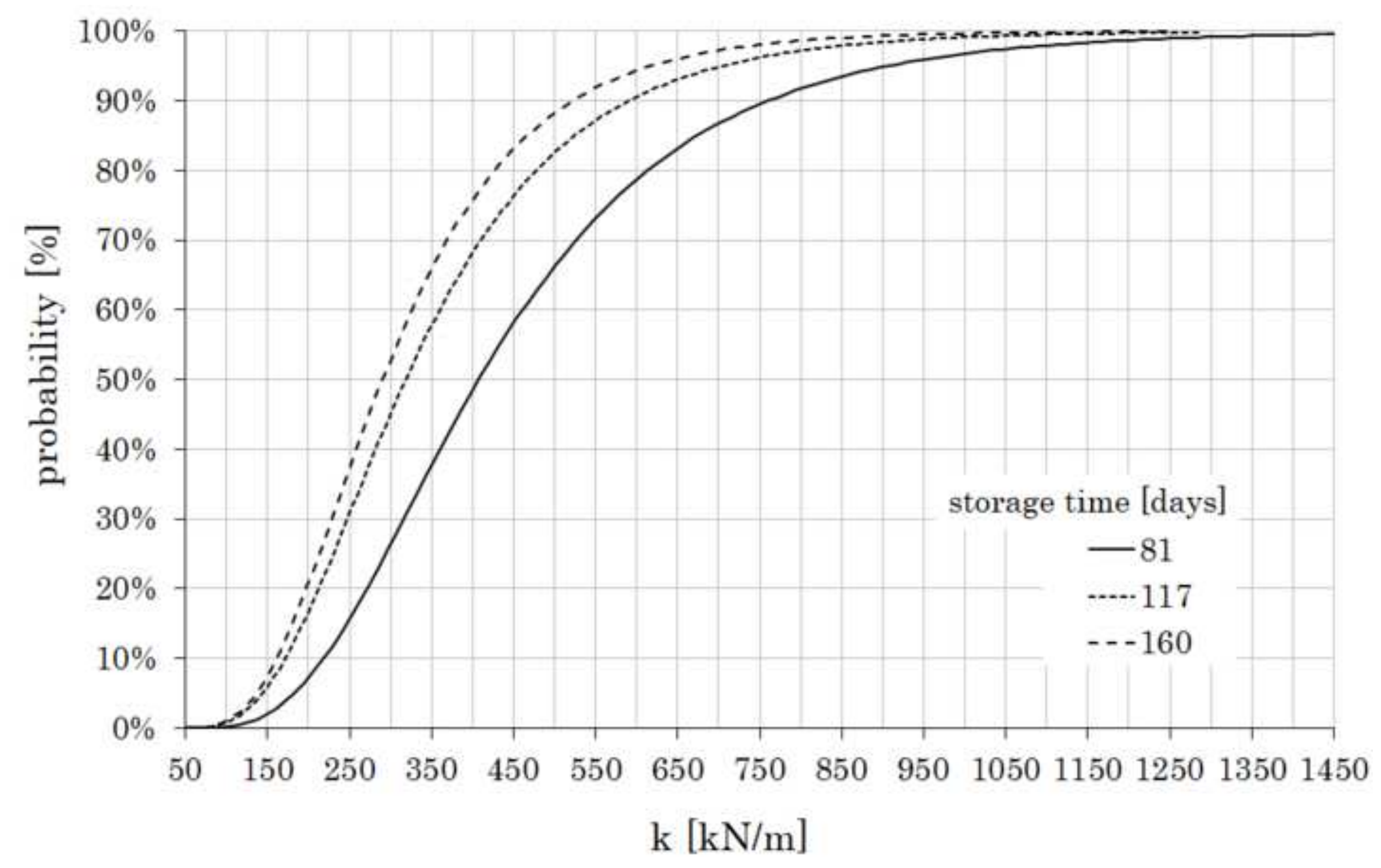




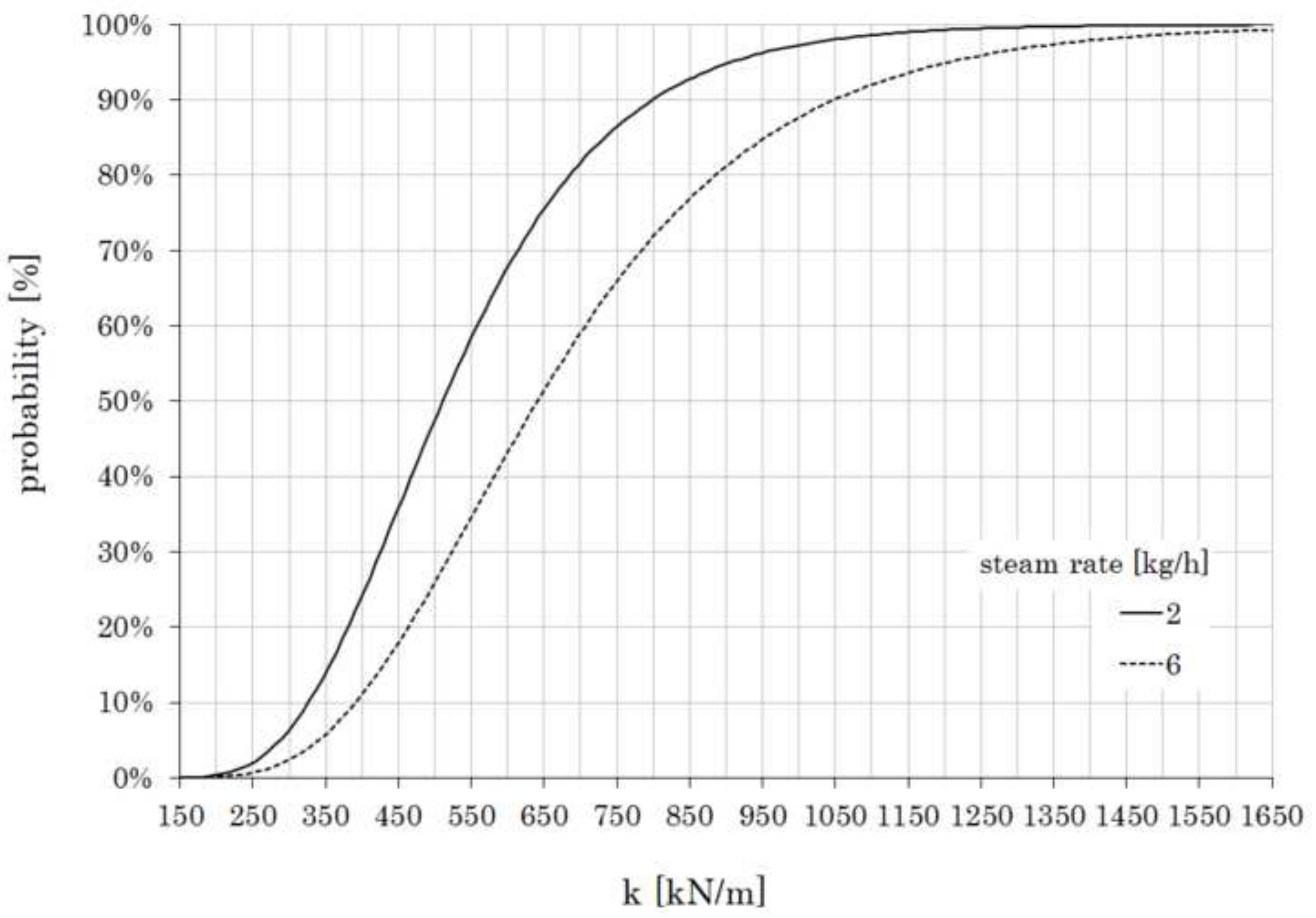




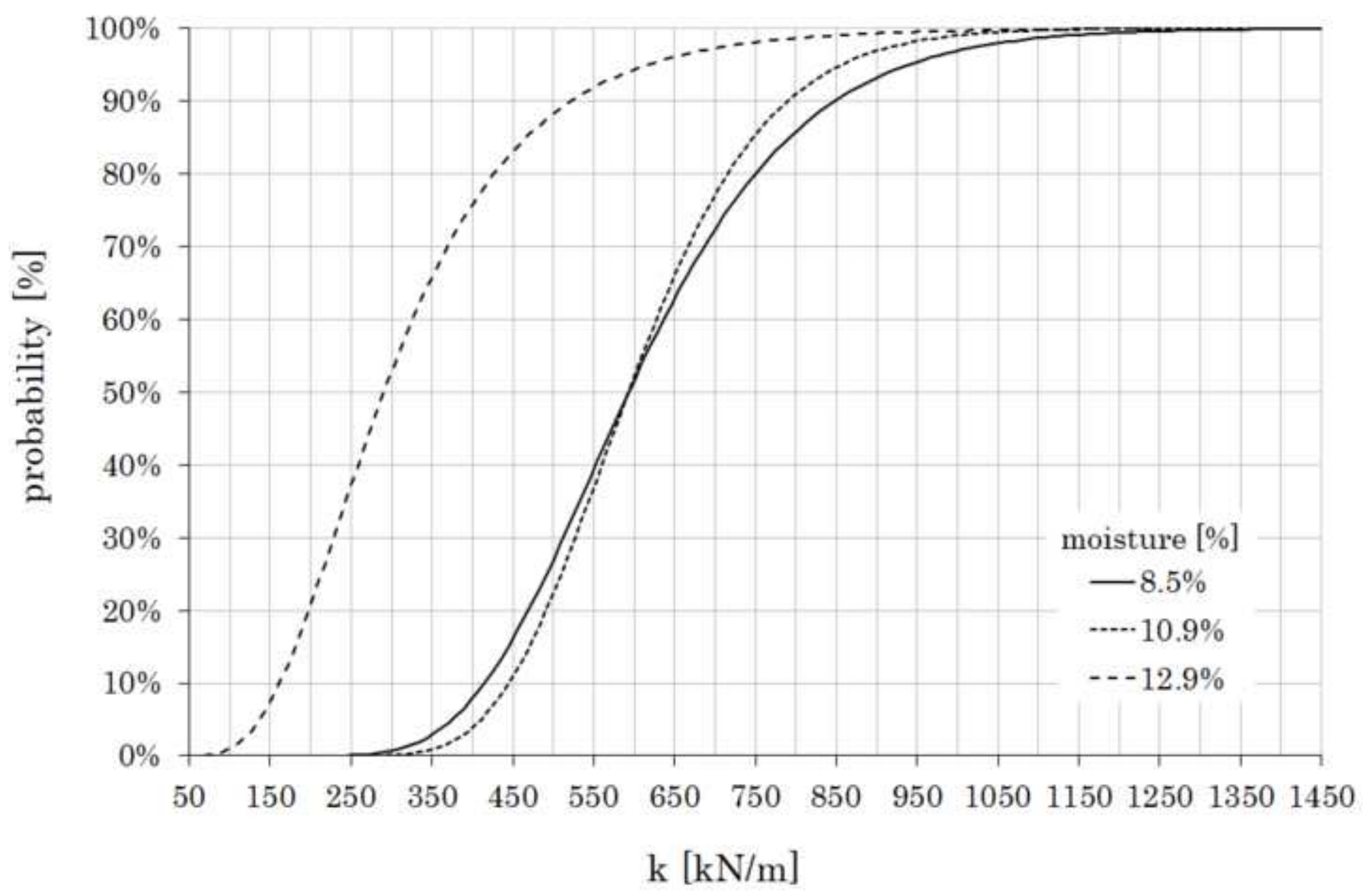

$\mathrm{k}[\mathrm{kN} / \mathrm{m}]$ 


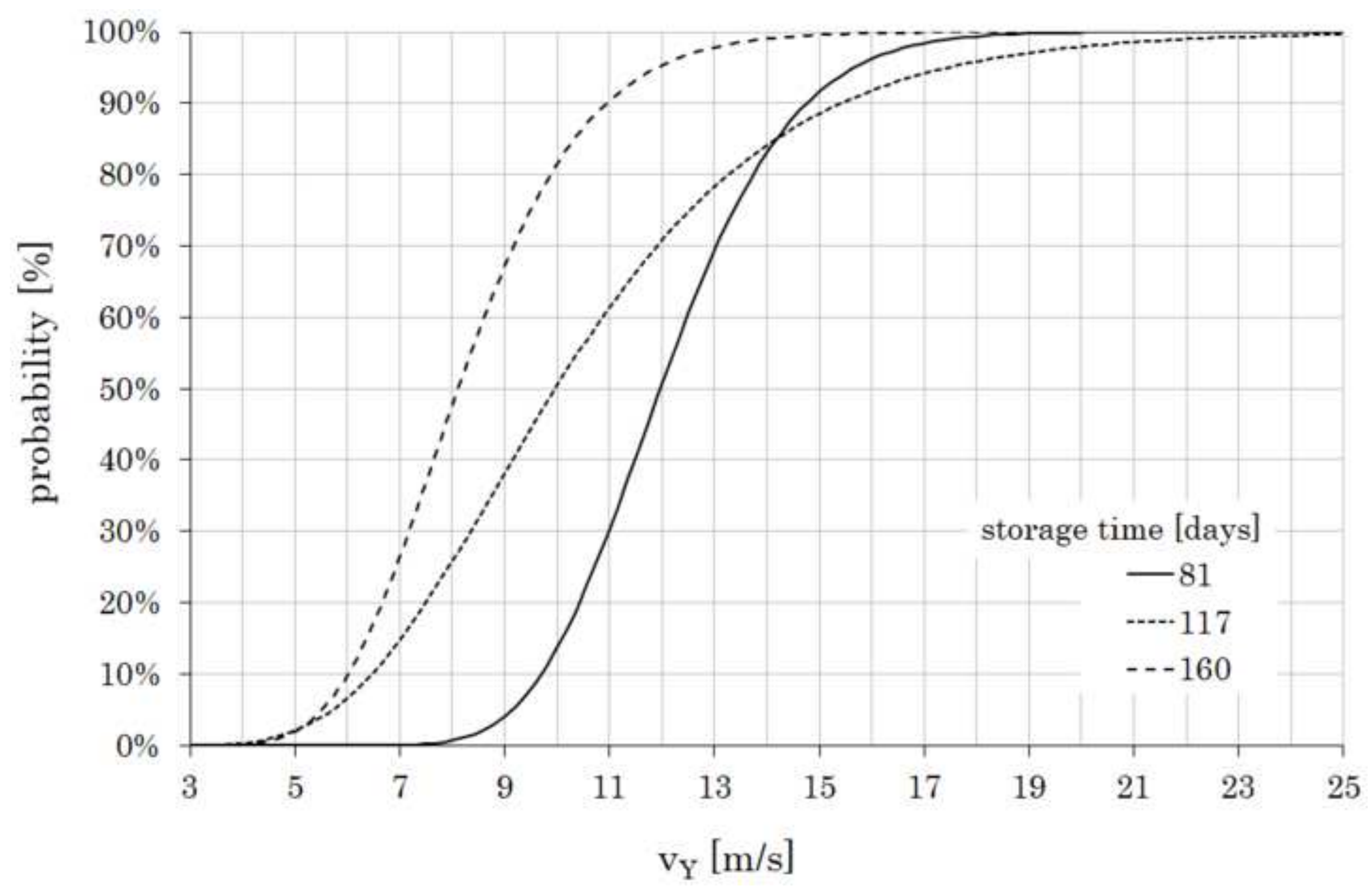




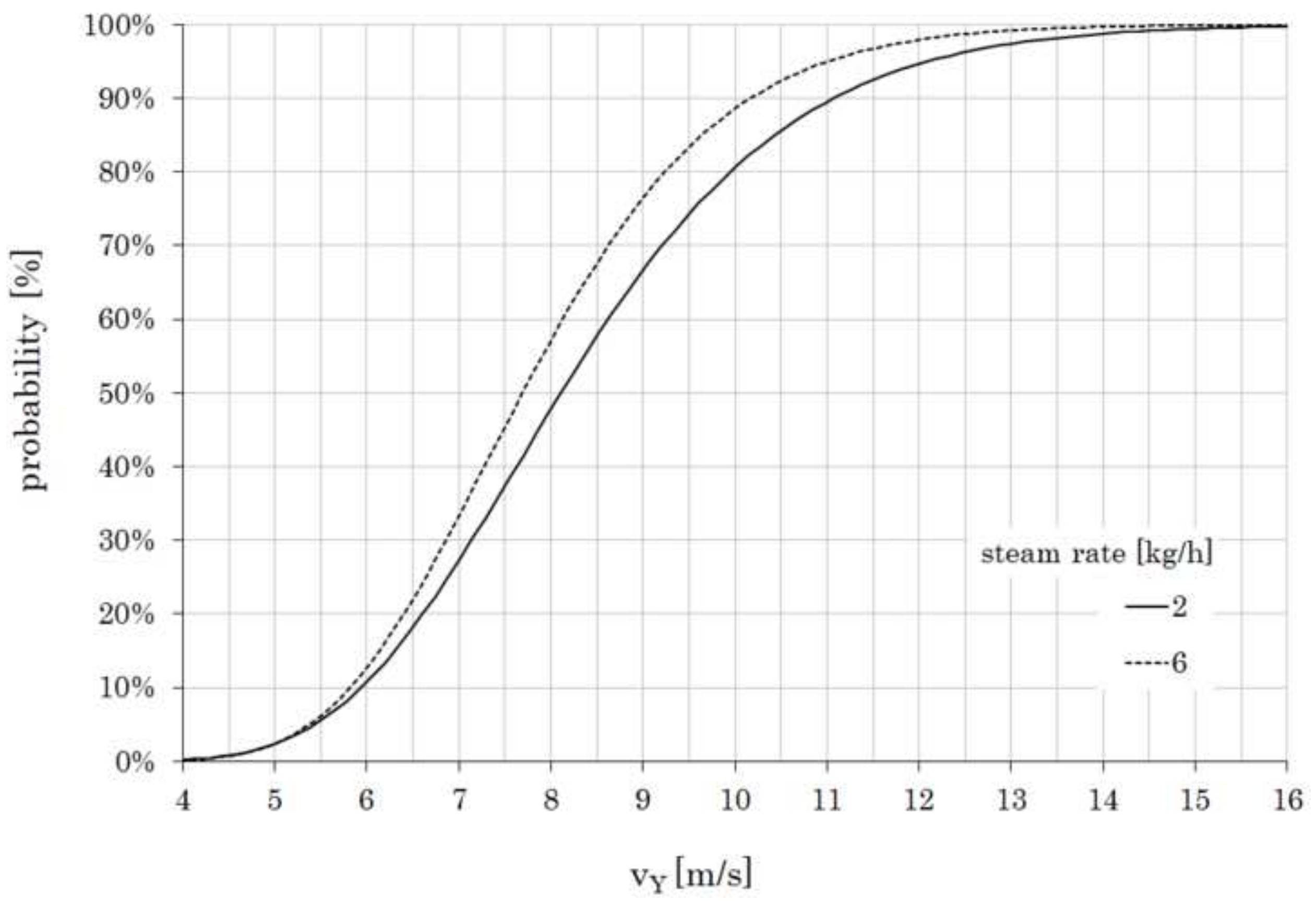




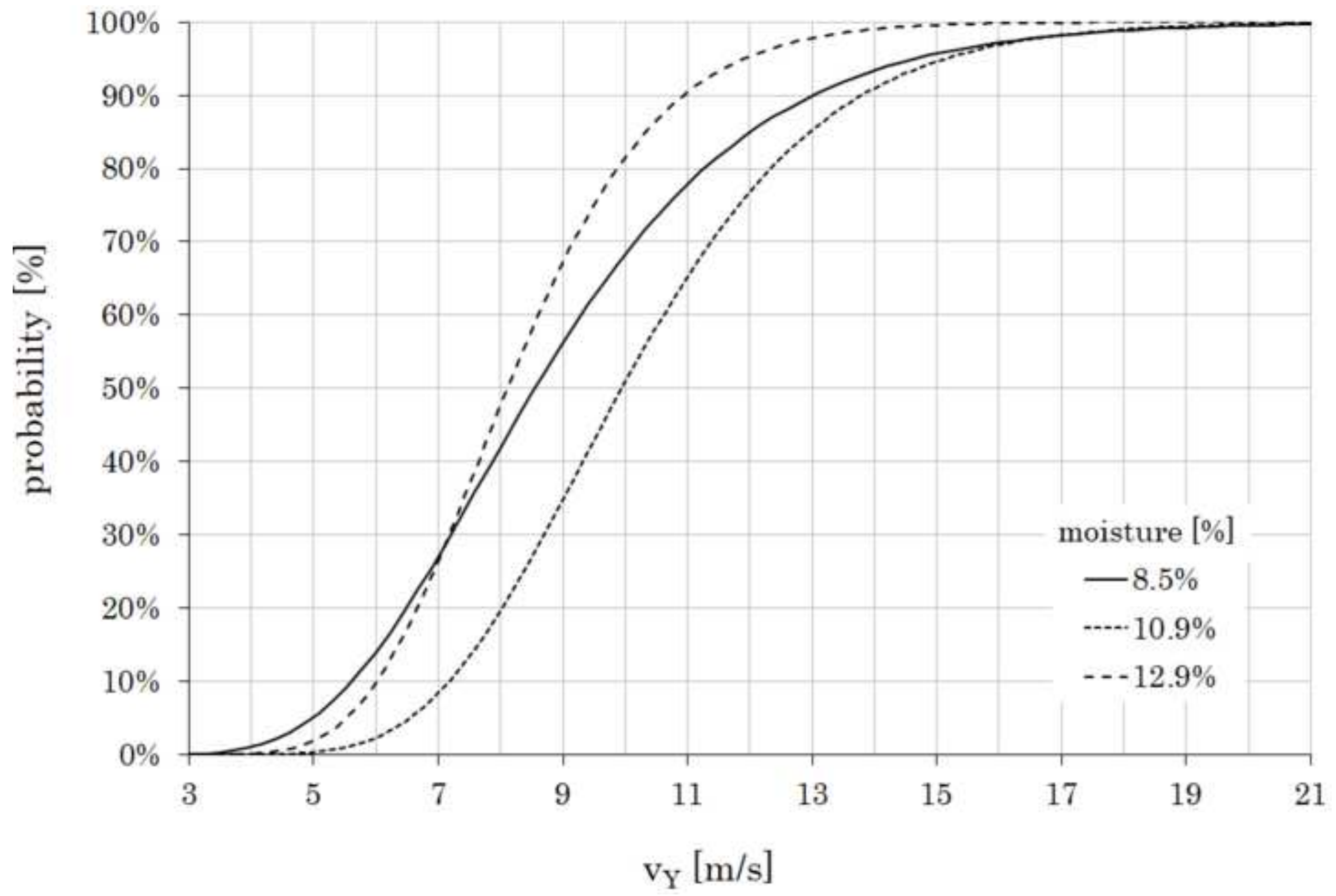




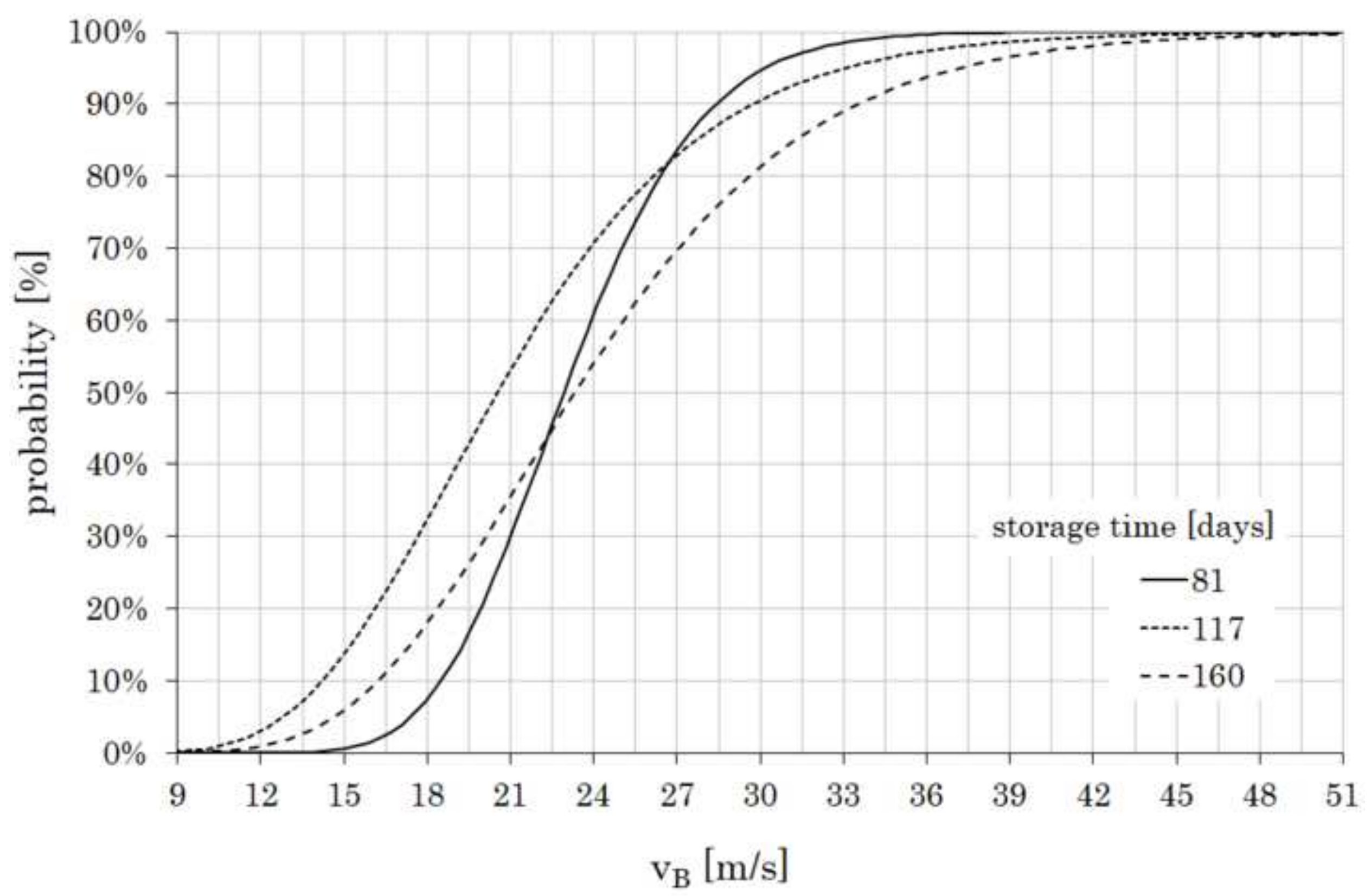




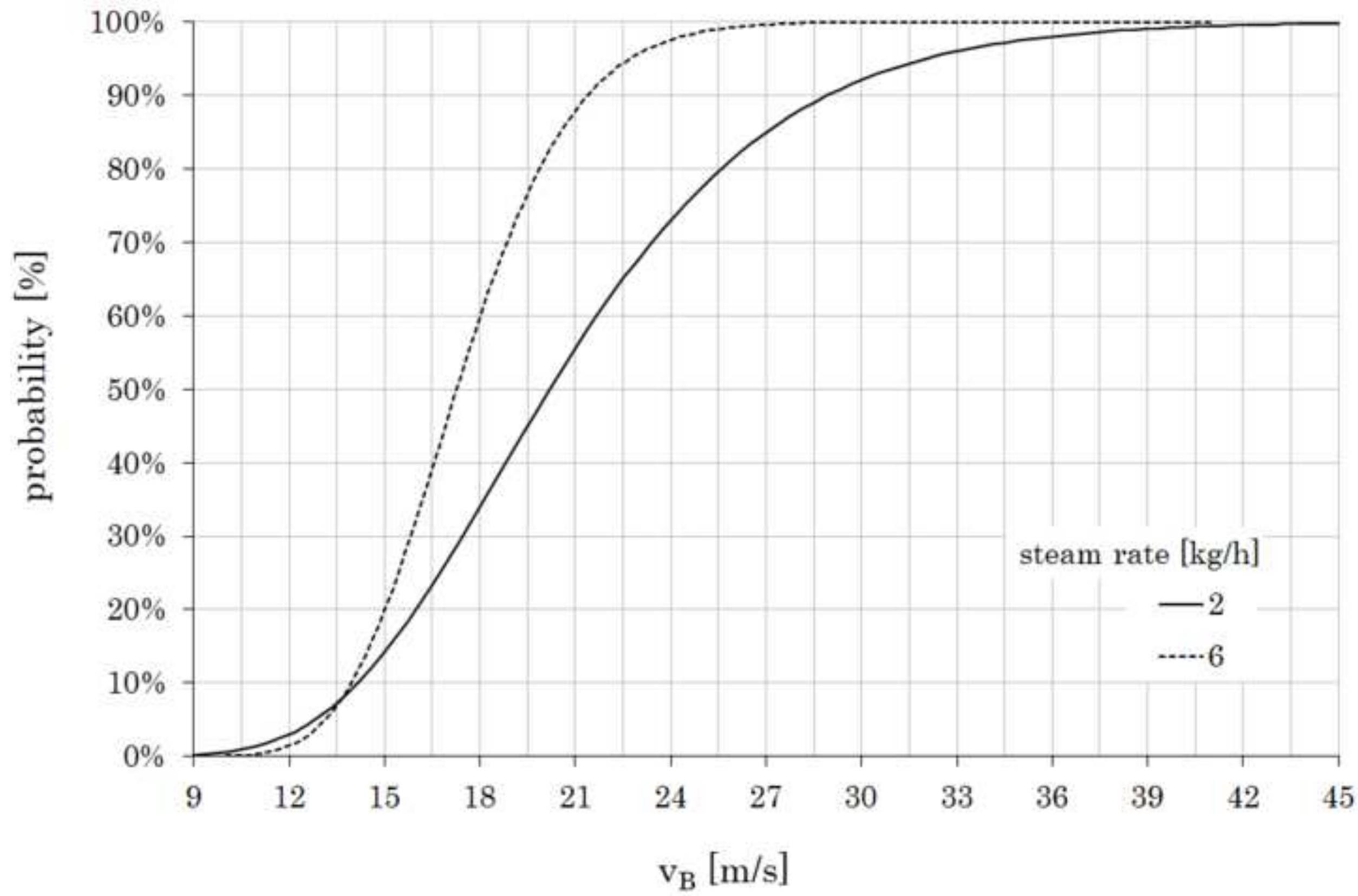




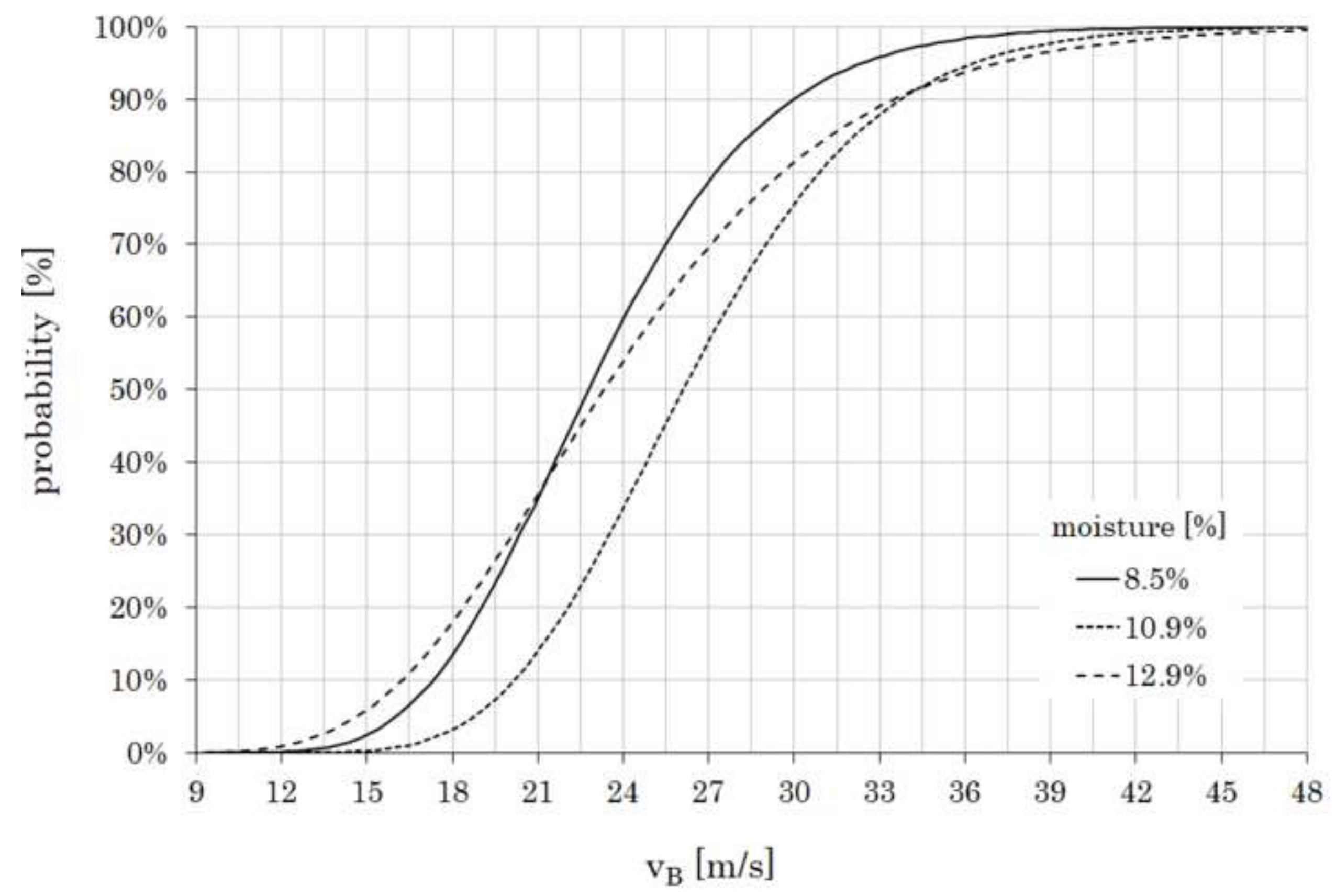

$\mathrm{v}_{B}[\mathrm{~m} / \mathrm{s}]$ 
Figure 7
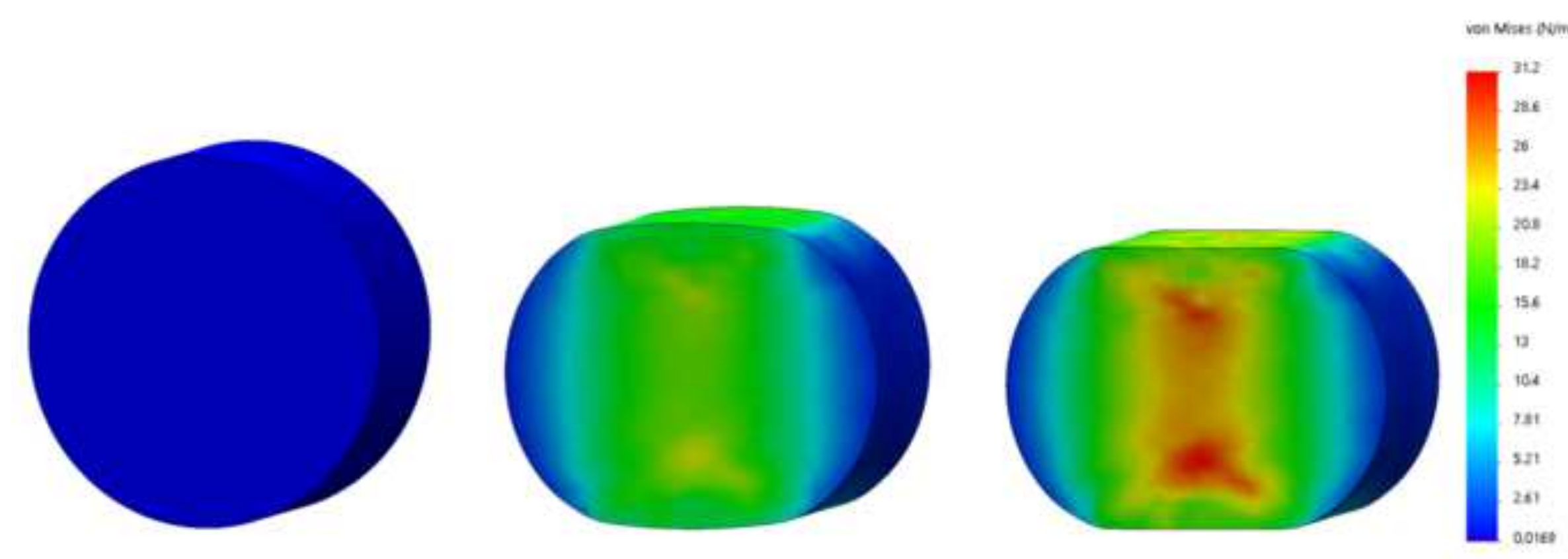

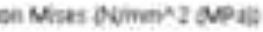

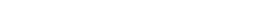


Table 1: $\quad$ Summary of production settings and resulting physical and mechanical properties of the pellet samples.

\begin{tabular}{|c|c|c|c|c|c|c|c|}
\hline \multirow{2}{*}{$\begin{array}{l}\text { Sample ID } \\
\\
\text { Assigned } \\
\text { name }\end{array}$} & \multicolumn{4}{|c|}{ Production settings and physical properties } & \multicolumn{3}{|c|}{$\begin{array}{l}\text { Sample durability (reproduced from Larsson and Samuelsson, } \\
\qquad \text { 2017) }\end{array}$} \\
\hline & $\begin{array}{l}\text { Storage } \\
\text { time } \\
\text { [days] }\end{array}$ & $\begin{array}{l}\text { Steam } \\
\text { rate } \\
{[\mathrm{kg} / \mathrm{h}]}\end{array}$ & $\begin{array}{c}\text { Feedstock } \\
\text { moisture } \\
\text { content } \\
\text { [wt\%] }\end{array}$ & $\begin{array}{c}\text { Pellet density } \\
\text { (reproduced from } \\
\text { Larsson and } \\
\text { Samuelsson, } \\
2017 \text { ) } \\
{\left[\mathrm{kg} / \mathrm{m}^{3}\right]}\end{array}$ & $\begin{array}{l}\text { according to ISO } \\
\text { 17831-1:2015's } \\
\text { tumbling test } \\
(n=20)[w t \%]\end{array}$ & $\begin{array}{l}\text { Ligno test } \\
(n=20)[w t \%]\end{array}$ & $\begin{array}{c}\text { Geometry-specific } \\
\text { breakage force } \\
{[\mathrm{N} / \mathrm{cm}]}\end{array}$ \\
\hline PPT 17 & 46 & 2 & 11.5 & $1.22 \pm 0.05$ & $89.7 \pm 6.46$ & $84.1 \pm 16.7$ & $452 \pm 174$ \\
\hline PPT 20 & 46 & 6 & 11.5 & $1.25 \pm 0.04$ & $91.4 \pm 10.7$ & $82.7 \pm 14.9$ & $604 \pm 184$ \\
\hline PPT 34 & 81 & 2 & 8.1 & $1.24 \pm 0.05$ & $84.6 \pm 14.7$ & $92.3 \pm 5.34$ & $466 \pm 128$ \\
\hline PPT 30 & 81 & 2 & 10.6 & $1.18 \pm 0.06$ & $90.2 \pm 5.83$ & $89.1 \pm 10.3$ & $389 \pm 144$ \\
\hline PPT 36 & 81 & 6 & 8.5 & $1.27 \pm 0.03$ & $91.6 \pm 5.08$ & $93.7 \pm 6.48$ & $484 \pm 144$ \\
\hline PPT 31 & 81 & 6 & 10.1 & $1.14 \pm 0.06$ & $94.9 \pm 3.13$ & $96.5 \pm 2.96$ & $374 \pm 173$ \\
\hline PPT 28 & 81 & 6 & 12.9 & $1.17 \pm 0.06$ & $91.0 \pm 5.71$ & $86.6 \pm 16.5$ & $509 \pm 179$ \\
\hline PPT 44 & 117 & 2 & 13.1 & $1.23 \pm 0.023$ & $95.7 \pm 1.12$ & $96.2 \pm 3.77$ & $431 \pm 94.0$ \\
\hline PPT 42 & 117 & 6 & 8.8 & $1.20 \pm 0.03$ & $92.8 \pm 3.80$ & $96.0 \pm 5.58$ & $386 \pm 83.9$ \\
\hline PPT 45 & 117 & 6 & 12.8 & $1.14 \pm 0.05$ & $97.1 \pm 1.35$ & $98.6 \pm 0.78$ & $428 \pm 120$ \\
\hline PPT 47 & 117 & 6 & 12.8 & $1.12 \pm 0.08$ & $94.5 \pm 2.63$ & $97.2 \pm 2.32$ & $349 \pm 129$ \\
\hline PPT 53 & 160 & 2 & 8.2 & $1.23 \pm 0.03$ & $91.7 \pm 7.41$ & $95.7 \pm 5.03$ & $451 \pm 103$ \\
\hline РPT 61 & 160 & 2 & 12.9 & $1.19 \pm 0.04$ & $97.6 \pm 1.22$ & $99.0 \pm 0.53$ & $497 \pm 111$ \\
\hline PPT 55 & 160 & 6 & 8.5 & $1.24 \pm 0.04$ & $96.3 \pm 1.46$ & $98.2 \pm 1.18$ & $516 \pm 112$ \\
\hline РPT 68 & 160 & 6 & 10.6 & $1.23 \pm 0.03$ & $96.3 \pm 1.45$ & $98.5 \pm 0.91$ & $560 \pm 68.5$ \\
\hline PPT 63 & 160 & 6 & 12.9 & $1.12 \pm 0.06$ & $97.0 \pm 1.97$ & $98.4 \pm 1.91$ & $383 \pm 103$ \\
\hline
\end{tabular}


Table 1: $\quad$ Summary of the simulation model details.

\begin{tabular}{|c|c|c|}
\hline Assigned property & Stainless steel punches & Wood pellet sample \\
\hline Length [mm] & 5 & 4.5 \\
\hline Diameter $[\mathrm{mm}]$ & 25 & 8.08 \\
\hline Solid density $\left[\mathrm{kg} \cdot \mathrm{m}^{3}\right]$ & $\begin{array}{l}7750 \text { (taken from SOLIDWORKS material } \\
\text { library) }\end{array}$ & 510 (taken from Witomski et al., 2014) \\
\hline Mechanical nature & Linear elastic & Linear elastic \\
\hline Young's modulus [MPa] & $\begin{array}{l}1.93 \cdot 10^{5} \text { (taken from SOLIDWORKS } \\
\text { material library) }\end{array}$ & $\begin{array}{l}97.79 \text { (measured for PPT } 36 \text { in this study according to } \\
\text { Eq. (2), see Table A) }\end{array}$ \\
\hline Poisson's ratio [-] & $\begin{array}{l}0.3 \text { (taken from SOLIDWORKS material } \\
\text { library) }\end{array}$ & 0.4 (taken from Kretschmann and Green, 1996) \\
\hline Mesh elements [-] & 235072 & 11857 \\
\hline Model geometry volume $\left[\mathrm{mm}^{3}\right]$ & 4908.8 & 230.74 \\
\hline Volume of elements $\left[\mathrm{mm}^{3}\right]$ & 4907.4 & 230.08 \\
\hline Total mass $[\mathrm{g}]$ & 38.278 & 0.11734 \\
\hline
\end{tabular}




\section{Appendix}

Table A: $\quad$ Summary of the model-based evaluated mechanical properties

\begin{tabular}{|c|c|c|c|c|c|c|}
\hline Sample ID & $\begin{array}{c}\text { Elastic stiffness } \\
k[k N / m]\end{array}$ & $\begin{array}{l}\text { Modulus of elasticity } \\
\qquad \mathrm{E}[\mathrm{MPa}]\end{array}$ & $\begin{array}{c}\text { Strain energy } \\
\text { initiating yield } \\
W_{y}[\mathrm{~mJ}]\end{array}$ & $\begin{array}{c}\text { Strain energy initiating } \\
\text { breakage } \\
W_{B}[\mathrm{~mJ}]\end{array}$ & $\begin{array}{c}\text { Collision velocity } \\
\text { initiating yield } \\
v_{y}[\mathrm{~m} / \mathrm{s}]\end{array}$ & $\begin{array}{c}\text { Collision velocity } \\
\text { initiating breakage } \\
\qquad v_{B}[\mathrm{~m} / \mathrm{s}]\end{array}$ \\
\hline PPT 17 & $614.38 \pm 275.21$ & $111.09 \pm 49.76$ & $25.68 \pm 17.93$ & $78.79 \pm 41.55$ & $9.12 \pm 2.97$ & $16.25 \pm 4.20$ \\
\hline PPT 20 & $750.64 \pm 279.54$ & $135.73 \pm 50.54$ & $24.72 \pm 13.29$ & $142.70 \pm 97.43$ & $9.09 \pm 2.41$ & $21.48 \pm 7.07$ \\
\hline PPT 28 & $452.47 \pm 206.82$ & $81.81 \pm 37.40$ & $41.83 \pm 10.52$ & $154.79 \pm 48.56$ & $12.1 \pm 1.71$ & $23.21 \pm 3.75$ \\
\hline PPT 30 & $495.26 \pm 250.27$ & $89.55 \pm 45.25$ & $26.284 \pm 16.90$ & $112.87 \pm 62.68$ & $9.23 \pm 2.99$ & $19.31 \pm 5.56$ \\
\hline PPT 31 & $389.45 \pm 150.39$ & $70.42 \pm 27.19$ & $21.48 \pm 17.42$ & $122.14 \pm 113.19$ & $8.27 \pm 2.93$ & $19.39 \pm 7.91$ \\
\hline PPT 34 & $680.29 \pm 214.47$ & $123.01 \pm 38.78$ & $17.94 \pm 6.61$ & $88.17 \pm 29.26$ & $7.85 \pm 1.55$ & $17.50 \pm 2.91$ \\
\hline PPT 36 & $540.81 \pm 190.53$ & $97.79 \pm 34.45$ & $20.70 \pm 10.96$ & $130.70 \pm 93.20$ & $8.34 \pm 2.11$ & $20.63 \pm 6.52$ \\
\hline PPT 42 & $479.49 \pm 89.23$ & $86.70 \pm 16.13$ & $15.78 \pm 6.12$ & $94.36 \pm 58.72$ & $7.37 \pm 1.42$ & $17.65 \pm 5.12$ \\
\hline PPT 44 & $462.36 \pm 87.90$ & $83.60 \pm 15.89$ & $21.29 \pm 11.62$ & $110.76 \pm 40.01$ & $8.40 \pm 2.36$ & $19.53 \pm 3.77$ \\
\hline PPT 45 & $508.77 \pm 226.88$ & $92.00 \pm 41.02$ & $33.00 \pm 15.90$ & $130.61 \pm 59.28$ & $10.56 \pm 2.56$ & $21.07 \pm 4.80$ \\
\hline PPT 47 & $353.69 \pm 163.99$ & $63.95 \pm 29.65$ & $33.92 \pm 25.62$ & $130.29 \pm 81.94$ & $10.37 \pm 3.76$ & $20.68 \pm 6.21$ \\
\hline PPT 53 & $703.22 \pm 605.83$ & $127.16 \pm 109.55$ & $11.97 \pm 5.06$ & $100.72 \pm 54.02$ & $6.39 \pm 1.40$ & $18.37 \pm 4.77$ \\
\hline PPT 55 & $615.50 \pm 175.07$ & $111.29 \pm 31.65$ & $27.36 \pm 33.21$ & $154.52 \pm 73.61$ & $9.08 \pm 3.98$ & $22.93 \pm 5.13$ \\
\hline PPT 61 & $490.01 \pm 186.58$ & $88.60 \pm 33.74$ & $24.58 \pm 16.69$ & $183.94 \pm 82.98$ & $8.87 \pm 3.05$ & $25.03 \pm 5.54$ \\
\hline PPT 63 & $318.81 \pm 139.41$ & $57.65 \pm 25.21$ & $20.17 \pm 7.97$ & $176.34 \pm 98.10$ & $8.30 \pm 1.76$ & $24.20 \pm 6.72$ \\
\hline PPT 68 & $606.85 \pm 136.01$ & $109.73 \pm 24.59$ & $31.33 \pm 15.76$ & $209.89 \pm 120.40$ & $10.26 \pm 2.61$ & $26.66 \pm 6.30$ \\
\hline
\end{tabular}

